\title{
A Randomised Controlled Trial of Computer-Assisted Interviewing in Sexual Health Clinics
}

John Richens, Clinical Lecturer*†, Andrew Copas, Senior Lecturer*, Syed Tariq Sadiq, Consultant $\ddagger \S$, Patricia Kingori, Research Fellow\|, Ona McCarthy, Research FellowdI, Victoria Jones, Research Fellow\|, Philip Hay, Consultant $\ddagger \S$, Kevin Miles, Nurse Consultant $\dagger$, Richard Gilson, Consultant*†, John Imrie, Associate Professor**, Mark Pakianathan, Consultant§

*Centre for Sexual Health and HIV Research, University College London, The Mortimer Market Centre, London WC1E 6JB

$†$ Camden Primary Care Trust, St Pancras Hospital

4 St Pancras Way, London NW1 0PE

$\ddagger$ Centre for Infection, St George's, University of London

§The Courtyard Clinic, St George's Healthcare, NHS Trust, Blackshaw Road, Tooting, London, SW17 0QT

||London School of Hygiene \& Tropical Medicine, Keppel St, London, WC1E 7HT IResearch Department of Primary Health and Population Health, University College London, 2nd Floor, Holborn Union Building, Whittington Campus, Highgate Hill, London N19 5LW

**National Centre in HIV Social Research, Robert Webster Building, The University of New South Wales, Sydney NSW 2052 Australia 
Corresponding author and guarantor: John Richens, Centre for Sexual Health \& HIV

Research, The Mortimer Market Centre, Mortimer Market, London WC1E 6JB.

Telephone 0207380 9767. Fax 0207380 9778. jrichens@ gum.ucl.ac.uk

Running head: Computer-assisted sexual health interviewing (CASHI)

Word count (excluding abstract, references, Tables and Figure): 2584

Key Words: Sexually transmitted infections, Computer-assisted self-interview

(CASI), risk behaviour, electronic patient record (EPR) 


\section{Abstract}

Objectives: Impact of computer-assisted interview versus pen and paper on disclosure of sexual behaviour, diagnostic testing by clinicians, infections diagnosed and referral for counselling.

Design: Two-centre parallel 3-arm randomized controlled open trial. Computergenerated randomization with allocation concealment using sealed envelopes.

Setting: Two London teaching hospital sexual health clinics.

Participants: 2351 clinic attenders over age 16

Interventions: 1. Computer-assisted self-interview (CASI). 2. Computer-assisted personal interview (CAPI). 3. Pen and paper interview (PAPI).

Main outcome measures: diagnostic tests ordered, sexually transmitted infections (STIs)

Secondary outcomes: Disclosure of sexual risk, referral for counselling. Results: 801, 763 and 787 patients randomly allocated receive CASI, CAPI and PAPI. 795, 744 and 779 available for intention-to-treat analysis. Significantly more diagnostic testing for hepatitis B and C and rectal samples in the CAPI arm (Odds for more testing relative to PAPI 1.32 [95\% CI 1.09 to 1.59$])$. This pattern not seen among CASI patients. HIV testing significantly lower among CASI patients (Odds for less testing relative to PAPI 0.73 [95\% CI 0.59 to 0.90$]$ ). STI diagnoses not significantly different by trial arm. A summary measure of seven pre-specified sensitive behaviors found greater reporting with CASI (OR 1.4 [95\% CI 1.2 to 1.6]) and CAPI [OR 1.4 [95\% CI 1.2 to 1.7$]$ ) compared to PAPI.

Conclusions: CASI and CAPI can generate greater recording of risky behaviour than traditional PAPI. Increased disclosure did not increase STI diagnosis. Safeguards 
may be needed to ensure that clinicians are prompted to act upon disclosures made during self-interview.

Trial registration: ISRCTN: 97674664

Funding: Medical Research Council G0300707 


\section{Introduction}

Sexual health clinics combine treatment for sexually transmitted infections (STIs) with preventive work (tracing partners, advising about risk reduction). These functions are guided by information about sexual behavior disclosed by attenders. Experience gained in community based surveys of sexual behavior has indicated that disclosure of stigmatized sexual behaviors may increase when subjects have the opportunity to provide information to a computer. ${ }^{1-8}$ Similar observations have been reported from sexual health clinics. ${ }^{9-12}$ The consistency of these findings varies considerably across studies, some of which suggest that particular ethnic or age groups may respond differently ${ }^{13-15}$ while other studies have highlighted inconsistencies between all forms of self-report and biomarkers. ${ }^{16}$ Computer-assisted self-interview (CASI) spares the interviewee the embarrassment of a face-to-face interview, makes it easier to introduce branching routes through a questionnaire, ensures all subjects receive a standardized interview and offers greater scope to develop multilingual questionnaires. ${ }^{2 ; 3 ; 17-19}$ Greater internal consistency and fewer missed questions have been reported when using CASI compared to pen-and-paper questionnaires. ${ }^{9 ; 20}$ At present face-to-face interviewing remains the norm in UK sexual health clinics despite growing evidence that individuals may prefer to disclose information about their sexual behavior in ways they feel to be less threatening. ${ }^{21}$ Computer-assisted interviewing methods also offer the opportunity to save clinic time and to move to an electronic patient record (EPR), which are important for clinics implementing programmes of extended access and preparing for service-wide information technology developments within Britain's National Health Service. 
The Computer Assisted Sexual Health Interviewing (CASHI) study was designed to investigate whether the increased disclosure associated with computer-assisted interviewing can deliver demonstrable benefits in relation to i) the investigation and diagnosis of STIs, ii) the identification of other reproductive health issues for female attenders such as unplanned pregnancy and need for emergency contraception, iii) referral to health advisors who undertake risk reduction counseling. Qualitative research on the acceptability of computer use to patients and clinicians was also undertaken and is being reported separately.

\section{Methods}

\section{Subjects}

The study was conducted at two large London sexual health clinics, the Mortimer Market Centre in a central London location, and the Courtyard Clinic, 9 miles away in south-west London. The Courtyard Clinic serves a younger population and offers more walk-in appointments. The Mortimer Market Centre is particularly favoured by gay men and offers more booked appointments. Male and female patients over the age of 16 attending with a new clinical episode were eligible. Patients were excluded if they had insufficient English or literacy to understand the recruitment process.

\section{Interventions}

Patients were randomized to be interviewed in one of three ways:

1. Computer-assisted self-interview (CASI), using a tablet (touchscreen) computer in private. The electronic interview followed the format of the clinical proforma used by clinicians at each clinic for standard care. The 
patient would then be assessed by a clinician provided with a print-out generated from the interview.

2. Computer-assisted personal interview (CAPI), patient and clinician viewing the screen together, using the same interview as in the CASI, but with data input by the clinician. On completion of the interview the clinician generated a print-out to place in the clinic notes.

3. Pen and paper interview (PAPI) with a clinician following the normal clinic practice of completing a proforma with the patient (usual care arm). The data from the clinic notes was subsequently transferred into same electronic format as the CASI and CAPI interviews by research staff.

The data collected in all trial arms was based on the existing clinical notes proforma in use at each clinic. Computer-assisted interviews were developed and administered using the Questionnaire Development System provided by the Nova Research Company (Bethesda, MD, USA).

\section{Recruitment and Randomization}

Recruitment alternated between male and females clinics at each site on a weekly basis. Recruitment started in June 2005 and closed in July 2006. One full-time researcher at each site approached consecutive patients in the waiting areas, inviting them to participate. Following patient consent, research staff opened sealed numbered envelopes prepared by the trial statistician to inform patients about their trial arm allocation. Randomly permuted blocks of varying size were used, stratified by site. 
Clinical staff

Clinical staff at the two clinics involved in the study included all available nurse practitioners, junior doctors, staff grade physicians, specialist trainees and consultants. All staff were trained to use the electronic interview.

Laboratory testing

In this pragmatic trial, testing for Neisseria gonorrhoeae, Chlamydia trachomatis, Trichomonas vaginalis, Hepatitis $A, B$ and $C$ and $H I V$ was carried out according to established protocols in place at each clinic. The only variation was testing for $C$. trachomatis by nucleic acid amplification tests (NAAT) on throat and rectal samples and NAAT for N. gonorrhoeae on rectal samples made available to male and female trial participants who disclosed rectal or pharyngeal exposure.

Outcome measures

The primary outcome measures were:

1. Patterns of STI diagnostic testing in each arm. Diagnostic testing patterns were classified as "standard", "standard with HIV test" or "enhanced". The "standard" test comprised tests for gonorrhoea and chlamydia from urethral/cervical/urine sample, a test for trichomonas on vaginal sample, and a blood test for syphilis. "Enhanced" testing included additional tests for hepatitis B or hepatitis C or rectal samples for gonorrhoea and chlamydia, reserved for participants disclosing higher risk behaviour.

2. STI diagnoses.

Secondary outcome measures were: 
1. Uptake of testing for HIV, hepatitis B, hepatitis $\mathrm{C}$, rectal gonorrhoea and chlamydia.

2. Rates of diagnosis of HIV, hepatitis B, hepatitis C, rectal gonorhoea and chlamydia.

3. Identification of indications for post-coital contraception

4. Referral to health advisers (sexual health counsellors).

5. Rates of disclosure of same sex partners, concurrent relationships, multiple partners, involvement in sex work, non-use of condoms with casual partners and anal sex.

Sample size and statistical analysis

We calculated that 2300 patients would provide $80 \%$ power to demonstrate as statistically significant a $35 \%$ relative increase in enhanced screening from an assumed uptake of 20 to $27 \%$ or a $27 \%$ relative increase in STI diagnoses from a prevalence of 30 to $38 \%$. The calculations were based on a significance level of $2 \%$, reduced from the usual $5 \%$ level to account for the multiple testing arising from comparing 3 pairs of study arms.

Analysis was based on the study arm to which the patient was randomised (intentionto-treat). The principal comparisons were the pairwise comparisons between study arms, with PAPI taken as the comparison arm as it is the current standard. The majority of outcomes are binary. For these the odds ratio for one study arm relative to the other were used as the measure of effect, and these were adjusted for gender and clinic venue through logistic regression. For the first primary outcome (patterns of STI diagnostic testing), with 3 ordered categories, ordinal regression was used. The 
odds ratio was also used as the measure of effect, calculated under an assumption of proportional odds. To measure the effect of an interview method relative to another for the behavioral outcomes, a summary odds ratio was calculated, pooling information from seven outcomes. This was done using generalized estimation equations (GEE), as was successfully applied to an earlier study to compare reporting between interview methods in the general population. ${ }^{20}$ As a subsidiary analysis, odds ratios were also calculated for each individual behavioral outcome, and testing for heterogeneity was done to establish whether the difference between study arms was broadly similar across the seven behaviors or not. As a form of subgroup analysis, tests were carried out to see whether differences between arms varied by gender or by clinic. 


\section{Results}

Figure 1 shows the flow of patients through the study in each trial arm. The most common deviations from protocol were patients allocated to CAPI who received PAPI instead as a result of difficulties encountered by clinicians in using the CAPI programme.

\section{Table 1. Demographic features of trial participants}

\begin{tabular}{|c|c|c|c|c|}
\hline & & Mortimer & Courtyard & $\mathrm{P}$ value \\
\hline & & Market & Clinic & \\
\hline Patients & & 1079 & 1239 & \\
\hline randomized & & & & \\
\hline Male & & $48.6 \%$ & $48.8 \%$ & 0.90 \\
\hline Non-UK origin & & $44.3 \%$ & $32.3 \%$ & $<0.001$ \\
\hline Same sex & & $27.5 \%$ & $5.7 \%$ & $<0.001$ \\
\hline partner & & & & \\
\hline Age & $<25$ years & $28.9 \%$ & $35.9 \%$ & ) \\
\hline & $25-34$ years & $45.3 \%$ & $46.1 \%$ & \}$<0.001$ \\
\hline & $>35$ years & $25.7 \%$ & $17.9 \%$ & \\
\hline
\end{tabular}

Demographic features of 2318 subjects who participated (Table 1), show patients at the Courtyard Clinic were significantly younger and patients at the Mortimer Market Centre significantly more likely to be of overseas origin or to report same sex partners. 
Primary outcomes (Table 2)

Table 2. Primary Outcomes - Patterns of screening, STI diagnoses

\begin{tabular}{|c|c|c|c|c|c|c|}
\hline \multirow[t]{2}{*}{$\begin{array}{l}\text { Primary } \\
\text { Outcomes }\end{array}$} & \multirow[b]{2}{*}{$\begin{array}{l}\mathrm{N} \\
(\%)\end{array}$} & \multicolumn{2}{|c|}{$\begin{array}{l}\text { Pen and paper } \\
\text { interview }\end{array}$} & \multicolumn{2}{|c|}{$\begin{array}{l}\text { Computer } \\
\text { assisted } \\
\text { physician } \\
\text { interview }\end{array}$} & \multirow{2}{*}{$\begin{array}{l}\text { Computer } \\
\text { assisted } \\
\text { self- } \\
\text { interview } \\
\text { OR }^{1} \\
(95 \% \mathrm{CI})\end{array}$} \\
\hline & & $\begin{array}{l}\text { OR } \\
(95 \% \\
\text { CI })\end{array}$ & $\begin{array}{l}\mathrm{N} \\
(\%)\end{array}$ & $\begin{array}{l}\mathrm{OR}^{1} \\
(95 \% \\
\mathrm{CI})\end{array}$ & $\begin{array}{l}\mathrm{N} \\
(\%)\end{array}$ & \\
\hline
\end{tabular}

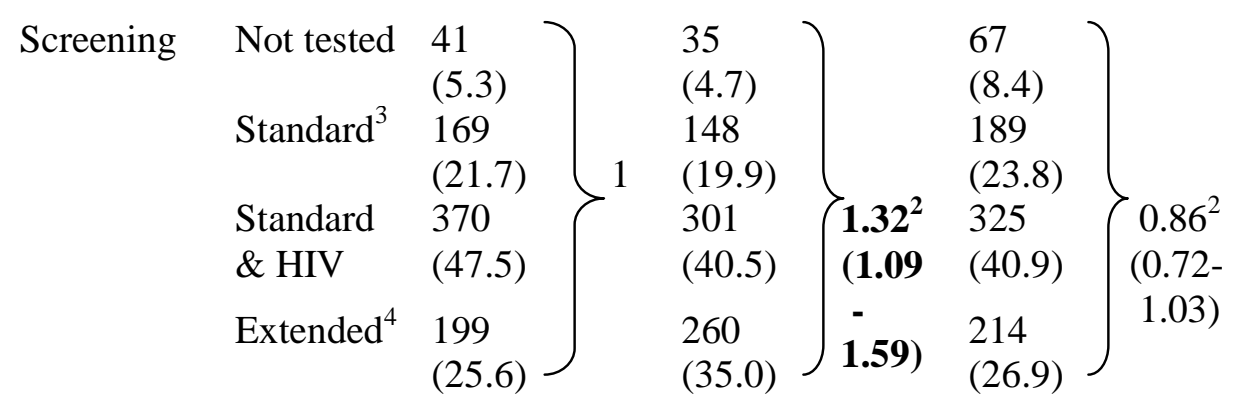

$\begin{array}{lllllll}\text { Any STI } & 78 & 1 & 82 & 1.12 & 80 & 0.96 \\ \text { positive } & (10.0) & & (11.0) & (0.80- & (10.1) & (0.69- \\ \text { test } & & & & 1.57) & & 1.34)\end{array}$

${ }^{1}$ Odds ratio relative to PAPI arm, adjusted for patient gender and recruitment clinic

${ }^{2}$ Calculated under the proportional odds assumption, i.e. the higher the ratio the greater the proportion of patients tested more comprehensively

${ }^{3}$ Tests for gonorrhoea and chlamydia from urethral/cervical/urine sample, test for trichomonas on vaginal sample, blood test for syphilis

${ }^{4}$ Indicates tests for hepatitis B or C, rectal tests for gonorrhoea or chlamydia

\section{Testing for sexually transmitted infections}

Screening tests for any STI were carried out at a significantly higher rate among patients in the CAPI arm compared to PAPI patients (OR 1.32 [95\% CI: 1.09-1.59]).

\section{Diagnosis of infection}

Diagnosis of STI was highest in the CAPI arm (11\%) but did not differ significantly between trial arms. 
Secondary outcomes (Tables 3 and 4)

Specific testing for hepatitis B (OR 1.65, 95\% CI 1.28-2.13) and hepatitis C (OR 3.36, 95\% CI 2.05-5.51) and rectal infections (OR 1.35, 95\% CI 1.0-1.82) was conducted significantly more often in CAPI patients while testing for HIV was significantly less in the CASI arm (OR 0.73, 95\% CI 0.59-0.90). There was no significant difference in the rates of diagnosis of these infections by trial arm. The number of women identifiable as potential candidates for post-coital contraception was significantly higher among CASI patients (OR 2.14, 95\% CI 1.46-3.13). Referral to health advisors did not differ significantly by trial arm. 
Table 3. Secondary Outcomes - STIs linked to high-risk behaviour, referral to health advisors, indications for emergency contraception

\begin{tabular}{|c|c|c|c|c|c|c|}
\hline \multirow[t]{2}{*}{$\begin{array}{l}\text { Secondary } \\
\text { Outcomes }\end{array}$} & \multicolumn{2}{|c|}{ Pen and Paper } & \multicolumn{2}{|c|}{$\begin{array}{l}\text { Computer-assisted } \\
\text { physician interview }\end{array}$} & \multicolumn{2}{|c|}{$\begin{array}{l}\text { Computer-assisted } \\
\text { self-interview }\end{array}$} \\
\hline & $\mathrm{N}(\%)$ & $\begin{array}{l}\text { OR } \\
(95 \% \\
\mathrm{CI})\end{array}$ & $\mathrm{N}(\%)$ & $\begin{array}{l}\mathrm{OR}^{1} \\
(95 \% \mathrm{CI})\end{array}$ & $\mathrm{N}(\%)$ & $\begin{array}{l}\mathrm{OR}^{1} \\
(95 \% \mathrm{CI})\end{array}$ \\
\hline $\begin{array}{l}\text { 1. STI } \\
\text { targeted by } \\
\text { enhanced } \\
\text { screen }^{2}\end{array}$ & $45(5.8)$ & $1-$ & $43(5.8)$ & $\begin{array}{l}1.01 \\
(0.65- \\
1.57)\end{array}$ & $37(4.7)$ & $\begin{array}{l}0.74 \\
(0.46- \\
1.16)\end{array}$ \\
\hline $\begin{array}{l}\text { 2. HIV test } \\
\text { uptake }\end{array}$ & $\begin{array}{l}540 \\
(69.3)\end{array}$ & $1-$ & $\begin{array}{l}512 \\
(68.8)\end{array}$ & $\begin{array}{l}0.98 \\
(0.78- \\
1.21)\end{array}$ & $\begin{array}{l}498 \\
(62.6)\end{array}$ & $\begin{array}{l}0.73 \\
(0.59- \\
0.90)\end{array}$ \\
\hline $\begin{array}{l}\text { 3. HBV test } \\
\text { uptake }\end{array}$ & $\begin{array}{l}127 \\
(16.3)\end{array}$ & $1-$ & $\begin{array}{l}180 \\
(24.2)\end{array}$ & $\begin{array}{l}1.65 \\
(1.28- \\
2.13)\end{array}$ & $\begin{array}{l}134 \\
(16.9)\end{array}$ & $\begin{array}{l}1.02 \\
(0.78- \\
1.33)\end{array}$ \\
\hline $\begin{array}{l}\text { 4. HCV test } \\
\text { uptake }\end{array}$ & $22(2.8)$ & $1-$ & $66(8.9)$ & $\begin{array}{l}3.36 \\
(2.05- \\
5.51)\end{array}$ & $26(3.3)$ & $\begin{array}{l}1.17 \\
(0.66- \\
2.09)\end{array}$ \\
\hline $\begin{array}{l}\text { 5. Rectal } \\
\text { sample taken }\end{array}$ & $\begin{array}{l}104 \\
(13.4)\end{array}$ & $1-$ & $\begin{array}{l}124 \\
(16.7)\end{array}$ & $\begin{array}{l}1.35 \\
(1.00- \\
1.82)\end{array}$ & $\begin{array}{l}113 \\
(14.2)\end{array}$ & $\begin{array}{l}1.01 \\
(0.75- \\
1.37)\end{array}$ \\
\hline $\begin{array}{l}\text { 6. Possible } \\
\text { indicator for } \\
\mathrm{EC}^{3} \text { (women } \\
\text { only) }\end{array}$ & $\begin{array}{l}49 \\
(12.1)\end{array}$ & $1-$ & $\begin{array}{l}65 \\
(16.9)\end{array}$ & $\begin{array}{l}1.49 \\
(1.00- \\
2.22)\end{array}$ & $\begin{array}{l}90 \\
(22.6)\end{array}$ & $\begin{array}{l}2.14 \\
(1.46- \\
3.13)\end{array}$ \\
\hline $\begin{array}{l}\text { 7. Health } \\
\text { advisor } \\
\text { attendance }\end{array}$ & $\begin{array}{l}119 \\
(15.3)\end{array}$ & $1-$ & $\begin{array}{l}103 \\
(13.8)\end{array}$ & $\begin{array}{l}0.89 \\
(0.67- \\
1.19)\end{array}$ & $\begin{array}{l}99 \\
(12.5)\end{array}$ & $\begin{array}{l}0.80 \\
(0.60- \\
1.06)\end{array}$ \\
\hline \multicolumn{7}{|c|}{${ }^{1}$ Odds ratio relative to PAPI arm, adjusted for patient gender and recruitment clinic } \\
\hline \multicolumn{7}{|c|}{${ }^{2}$ Hepatitis B, Hepatitis C, rectal gonorrhoea, rectal chlamydia } \\
\hline \multicolumn{7}{|c|}{$\begin{array}{l}{ }^{3} \text { Unprotected vaginal sex in last week, or emergency contraception (EC) given as } \\
\text { reason for attendance }\end{array}$} \\
\hline
\end{tabular}


Table 4 displays secondary outcomes relating to disclosure of risk behaviour. Of the seven risk behaviours selected prior to the study, three (having more than one partner in the past three months, having a history of concurrent sexual relationships and anal sex) were disclosed significantly more often in CASI and CAPI than in controls. A summary odds ratio across all seven behaviours showed significantly higher reporting with CASI (OR 1.41, 95\% CI 1.20 - 1.65) and CAPI (OR 1.42 95\% CI 1.21 - 1.66) compared to PAPI but no difference between CASI and CAPI. A test for heterogeneity of the differences between arms across behaviours highlighted that differences were especially marked for reporting of ever concurrent partnerships (see table 4). Excluding this behaviour the summary odds ratios were $1.21(1.05-1.39)$ for CAPI and $1.26(1.10-1.44)$ for CASI relative to PAPI. 
Table 4. Secondary Behaviour Disclosure Outcomes

\begin{tabular}{|c|c|c|c|c|c|c|}
\hline \multirow[t]{2}{*}{ Outcome } & \multicolumn{2}{|c|}{$\begin{array}{l}\text { Pen and paper } \\
\text { interview }\end{array}$} & \multicolumn{2}{|c|}{$\begin{array}{l}\text { Computer assisted } \\
\text { personal interview }\end{array}$} & \multicolumn{2}{|c|}{$\begin{array}{l}\text { Computer assisted self } \\
\text { interview }\end{array}$} \\
\hline & $\mathrm{N}(\%)$ & $\begin{array}{l}\text { OR } \\
(95 \% \\
\mathrm{CI})\end{array}$ & $\mathrm{N}(\%)$ & $\begin{array}{l}\mathrm{OR}^{1} \\
(95 \% \mathrm{CI})\end{array}$ & $\mathrm{N}(\%)$ & $\begin{array}{l}\mathrm{OR}^{1} \\
(95 \% \mathrm{CI})\end{array}$ \\
\hline $\begin{array}{l}2 \text { or more } \\
\text { partners in last } \\
3 \text { months }\end{array}$ & $\begin{array}{l}247 \\
(31.7)\end{array}$ & $1-$ & $\begin{array}{l}271 \\
(36.4)\end{array}$ & $\begin{array}{l}1.26 \\
(1.00- \\
1.57)\end{array}$ & $\begin{array}{l}308 \\
(38.7)\end{array}$ & $\begin{array}{l}1.35 \\
(1.08- \\
1.68)\end{array}$ \\
\hline $\begin{array}{l}\text { Ever } \\
\text { concurrent } \\
\text { partnerships }\end{array}$ & $62(8.0)$ & $1-$ & $\begin{array}{l}145 \\
(19.5)\end{array}$ & $\begin{array}{l}2.88 \\
(2.09- \\
3.97)\end{array}$ & $\begin{array}{l}127 \\
(16.0)\end{array}$ & $\begin{array}{l}2.19 \\
(1.59- \\
3.03)\end{array}$ \\
\hline $\begin{array}{l}\text { Same-sex } \\
\text { partner last } 3 \\
\text { months }\end{array}$ & $\begin{array}{l}108 \\
(13.9)\end{array}$ & $1-$ & $\begin{array}{l}107 \\
(14.4)\end{array}$ & $\begin{array}{l}1.10 \\
(0.78- \\
1.54)\end{array}$ & $\begin{array}{l}131 \\
(16.5)\end{array}$ & $\begin{array}{l}1.16 \\
(0.83- \\
1.61)\end{array}$ \\
\hline $\begin{array}{l}\text { Sold sex in last } \\
3 \text { months }\end{array}$ & $4(0.5)$ & $\mathrm{NA}^{2}$ & $5(0.7)$ & $\mathrm{NA}^{2}$ & $4(0.5)$ & $\mathrm{NA}^{2}$ \\
\hline $\begin{array}{l}\text { Paid for sex } \\
\text { last } 3 \text { months }\end{array}$ & $3(0.8)$ & $\mathrm{NA}^{2}$ & $6(1.7)$ & $\mathrm{NA}^{2}$ & $8(2.0)$ & $\mathrm{NA}^{2}$ \\
\hline $\begin{array}{l}\text { Unprotected } \\
\text { sex with casual } \\
\text { partner last } 3 \\
\text { months }\end{array}$ & $\begin{array}{l}99 \\
(12.7)\end{array}$ & $1-$ & $\begin{array}{l}91 \\
(12.2)\end{array}$ & $\begin{array}{l}0.96 \\
(0.70- \\
1.31)\end{array}$ & $\begin{array}{l}114 \\
(14.3)\end{array}$ & $\begin{array}{l}1.10 \\
(0.82- \\
1.49)\end{array}$ \\
\hline $\begin{array}{l}\text { Anal sex in last } \\
3 \text { months }\end{array}$ & $\begin{array}{l}124 \\
(15.9)\end{array}$ & $1-$ & $\begin{array}{l}166 \\
(22.3)\end{array}$ & $\begin{array}{l}1.63 \\
(1.24- \\
2.15)\end{array}$ & $\begin{array}{l}184 \\
(23.1)\end{array}$ & $\begin{array}{l}1.59 \\
(1.21- \\
2.09)\end{array}$ \\
\hline $\begin{array}{l}\text { Summary odds } \\
\text { ratio } \\
\text { (behaviours } \\
\text { above) }\end{array}$ & - & $1-$ & - & $\begin{array}{l}1.42 \\
(1.21- \\
1.66)\end{array}$ & - & $\begin{array}{l}1.41 \\
(1.20- \\
1.65)\end{array}$ \\
\hline $\begin{array}{l}\text { Injecting drug } \\
\text { user (IDU) }\end{array}$ & $7(0.9)$ & $\mathrm{NA}^{2}$ & $7(0.9)$ & $\mathrm{NA}^{2}$ & $2(0.3)$ & $\mathrm{NA}^{2}$ \\
\hline Sex with IDU & $6(0.8)$ & $\mathrm{NA}^{2}$ & $9(1.2)$ & $\mathrm{NA}^{2}$ & $4(0.5)$ & $\mathrm{NA}^{2}$ \\
\hline \multicolumn{7}{|c|}{${ }^{1}$ Odds ratio relative to PAPI arm, adjusted for patient gender and recruitment clinic } \\
\hline${ }^{2}$ Not calculated & due to sm & 11 numb & & & & \\
\hline
\end{tabular}


As a subgroup analysis we tested whether the differences between study arms varied by patient gender or by site across the various primary and secondary outcomes. We found only one statistically significant interaction, with p-value 0.045 , which may therefore have arisen by chance. The interaction found suggested that relative to PAPI, CAPI leads to more identifications of potential candidates for post-coital contraception among women at one site, but is similar to PAPI at the other. 


\section{Discussion}

The CASHI study was designed to test the hypothesis, based on other studies ${ }^{9-12}$ that utilized computer-assisted self interview, that patients would disclose more sensitive and clinically useful information when offered the option of computer assisted selfinterview (CASI), leading to more beneficial health outcomes. The odds of disclosure for seven key sensitive behaviours were found to be $40 \%$ greater when computerassisted interviewing was compared to pen and paper interviews (PAPI). Contrary to expectation, the CAPI interviews matched the CASI interviews for disclosure; the presence of a health worker did not reduce disclosure in the way that might be expected if social desirability was the major determinant of disclosure. The higher rate of diagnostic testing in the CAPI arm compared to the CASI arm, despite comparable disclosure of risky behaviour, was also unexpected. The extra testing observed did not lead to a higher rate of STI diagnosis. The lower rate of HIV testing in the CASI arm may be of concern to clinics aiming to encourage a high uptake of HIV testing among attenders.

The CASHI study goes beyond earlier studies of $\mathrm{CASI}^{9-12}$ which have focussed principally on disclosure, in extending its outcomes measures to clinician behaviour and subsequent health outcomes. The study has supports the use of electronic formats to collect data from patients attending sexual health services in the UK. Although it was not able to demonstrate significantly improved health outcomes, CASHI has shown that electronic formats encourage disclosure of sensitive information and thus have potential to improve patient management.

The following limitations apply to our findings: 
1. Many different formats for electronic interviews are possible for gathering the same dataset, such as wording of questions and whether respondents are given freedom to skip questions. Response rates are likely to vary with different electronic questionnaire formats.

2. Clinicians seeing patients recruited into the CASI and CAPI arms of the study were required to conduct consultations in a way that was new and different (and in the case of CAPI, rather unpopular). Had the study been conducted in an environment where these new approaches were more familiar and established, it is likely that more evolved working practices might have produced different results.

3. The power of the study to detect differences in STI diagnoses according to study arm will have been reduced by the $10 \%$ rates of STI among participants which proved to be $20 \%$ lower than anticipated.

Our study is thus in broad agreement with earlier studies ${ }^{9-12}$ which have demonstrated greater capture of sensitive information during computer assisted interviews and attributed this to reduction in social desirability bias. By including the CAPI arm it became possible to examine separately the impact of computer use per se and the impact of offering interview privacy on disclosure.

Two explanations should be considered for the high level of disclosure in the CAPI arm. First, patients knew information collected by CASI would be reviewed and discussed with them immediately afterwards by a clinician, so limiting the privacy element. Second, the impact of social desirability bias in a clinical setting might be substantially lower than that observed in community-based surveys of sexual 
behaviour. We suspect the overriding factor was the rigid structure of the electronic interview which affords less scope than the pen and paper to skip embarrassing questions. ${ }^{9}$ This effect may have been large enough to mask any effects of social desirability bias. The greater use of diagnostic tests in the CAPI arm suggests that the ordering of extra tests might be more likely to occur when the clinician elicits a full history from the patient in person rather than relying on self-interview data. An additional reason for the divergent use of diagnostic tests in CAPI and CASI patients may have arisen from the fact that recommendations for tests were displayed at the end of the CAPI interviews to patient and clinician simultaneously, facilitating discussion, whereas CASI patients viewed this recommendation on their own, prior to their face-to-face consultation We believe that safeguards could be introduced to alert clinicians if they do not follow recommended criteria for ordering tests. It would also be possible to re-design the CASI interview in a way that encourages the patient more strongly to commit to HIV testing and to draw the attention of clinicians to patients who have initially elected to opt out. Self-interview does to some extent, remove an important opportunity for patient and clinician to build rapport. ${ }^{22 ; 23}$ If it is embraced mechanisms will be required to divert those patients who particularly want or need to talk through an issue face to face towards a more traditional clinical pathway.

The challenges for the future are to demonstrate whether computerized interviewing can offer cost-effective improvements in health outcomes in sexual health services, to optimize the instruments for data collection and their integration into clinical pathways and consultations, to ensure that uptake of HIV testing is not diminished and to ensure that electronic data collection does not adversely affect patient-clinician interaction. 


\section{Key messages}

a Computer-assisted interviewing can encourage the disclosure of sexual risktaking

- This study noted a reduction in HIV testing among patients using computerassisted self interview

- Computer assisted interviewing was linked to additional STI testing without increasing the rate of STI diagnosis in this study 


\section{Acknowledgements}

This study required coordinated assistance from many individuals and organizations among whom we would especially like to thank:

For help with recruitment: Mortimer Market Centre - Maryjane Stevens, Kelsey Case, Ibi Fakoya

Courtyard Clinic - Marguerite Cockerell

For ensuring smooth running of the study: nurses, doctors and patients at the Mortimer Market Centre and Courtyard Clinic

Academic staff at the Centre for Sexual Health \& HIV research and St George's Hospital Medical School

\section{Contributors}

The study was designed and established by JR, AC, JI, KM, MP and STS.

Recruitment of patients and data collection was by PK, OM and JR. Data extraction was carried out by VJ. Data were analyzed by VJ and AC. The paper was written by JR with comments and contributions from all authors. All contributors approved the final version submitted for publication. JR was the guarantor.

\section{Funding}

Medical Research Council, Camden Primary Care Trust. Neither sponser was involved in the study design; in the collection, analysis, and interpretation of data; in the writing of the report; or in the decision to submit the paper for publication.

\section{Competing Interests}

None 


\section{Ethic approval}

The study was given ethical approval by the Medical Research Ethics Committee for Wales. 
Reference List

(1) Tourangeau R, Smith TW. Asking sensitive questions - The impact of data collection mode, question format, and question context. Public Opinion Quarterly 1996; 60(2):275-304.

(2) Turner CF, Ku L, Rogers SM, Lindberg LD, Pleck JH, Sonenstein FL. Adolescent sexual behavior, drug use, and violence: Increased reporting with computer survey technology. Science 1998; 280(5365):867-873.

(3) Des Jarlais DC, Paone D, Milliken J, Turner CF, Miller H, Gribble J et al. Audio-computer interviewing to measure risk behaviour for HIV among injecting drug users: a quasi-randomised trial. Lancet 1999; 353(9165):16571661.

(4) Simoes AA, Bastos FI, Moreira RI, Lynch KG, Metzger DS. A randomized trial of audio computer and in-person interview to assess HIV risk among drug and alcohol users in Rio De Janeiro, Brazil. Journal of Substance Abuse Treatment 2006; 30(3):237-243.

(5) van Griensven F, Naorat S, Kilmarx PH, Jeeyapant S, Manopaiboon C, Chaikummao $\mathrm{S}$ et al. Palmtop-assisted self-interviewing for the collection of sensitive behavioral data: Randomized trial with drug use urine testing. American Journal of Epidemiology 2006; 163(3):271-278.

(6) Le LC, Blum RW, Magnani R, Hewett PC, Do HM. A pilot of audio computer-assisted self-interview for youth reproductive health research in Vietnam. Journal of Adolescent Health 2006; 38(6):740-747.

(7) Villarroel MA, Turner CF, Rogers SM, Roman AM, Cooley PC, Steinberg AB et al. T-ACASI reduces bias in STD measurements: The National STD and Behavior Measurement Experiment. Sexually Transmitted Diseases 2008; 35(5):499-506.

(8) Hewett PC, Mensch BS, Ribeiro MCSD, Jones HE, Lippman SA, Montgomery MR et al. Using sexually transmitted infection biomarkers to validate reporting of sexual behavior within a randomized, experimental evaluation of interviewing methods. American Journal of Epidemiology 2008; 168(2):202-211.

(9) Kurth AE, Martin DP, Golden MR, Weiss NS, Heagerty PJ, Spielberg F et al. A comparison between audio computer-assisted self-interviews and clinician interviews for obtaining the sexual history. Sexually Transmitted Diseases 2004; 31(12):719-726.

(10) Kissinger P, Rice J, Farley T, Trim S, Jewitt K, Margavio V et al. Application of computer-assisted interviews to sexual behavior research. American Journal of Epidemiology 1999; 149(10):950-954. 
(11) Ghanem KG, Hutton HE, Zenilman JM, Zimba R, Erbelding EJ. Audio computer assisted self interview and face to face interview modes in assessing response bias among STD clinic patients. Sexually Transmitted Infections 2005; 81(5):421-425.

(12) Tideman RL, Chen MY, Pitts MK, Ginige S, Slaney M, Fairley CK. A randomised controlled trial comparing computer-assisted with face-to-face sexual history taking in a clinical setting. Sexually Transmitted Infections 2007; 83(1):52-56.

(13) Potdar R, Koenig MA. Does Audio-CASI improve reports of risky behavior? Evidence from a randomized field trial among young urban men in India. Studies in Family Planning 2005; 36(2):107-116.

(14) Jaya, Hindin MJ, Ahmed S. Differences in young people's reports of sexual behaviors according to interview methodology: A randomized trial in India. American Journal of Public Health 2008; 98(1):169-174.

(15) Hewitt M. Attitudes toward interview mode and comparability of reporting sexual behavior by personal interview and audio computer-assisted selfinterviewing - Analyses of the 1995 National Survey of Family Growth. Sociological Methods \& Research 2002; 31(1):3-26.

(16) Minnis AM, Steiner MJ, Gallo MF, Warner L, Hobbs MM, van der Straten A et al. Biomarker Validation of Reports of Recent Sexual Activity: Results of a Randomized Controlled Study in Zimbabwe. American Journal of Epidemiology 2009; 170(7):918-924.

(17) Webb PM, Zimet GD, Fortenberry JD, Blythe MJ. Comparability of a computer-assisted versus written method for collecting health behavior information from adolescent patients. Journal of Adolescent Health 1999; 24(6):383-388.

(18) Newman JC, Jarlais D, Turner CF, Gribble J, Cooley P, Paone D. The differential effects of face-to-face and computer interview modes. American Journal of Public Health 2002; 92(2):294-297.

(19) Turner CF, Rogers SM, Hendershot TP, Miller HG, Thornberry JP. Improving representation of linguistic minorities in health surveys. Public Health Reports 1996; 111(3):276-279.

(20) Johnson AM, Copas AJ, Erens B, Mandalia S, Fenton K, Korovessis C et al. Effect of computer-assisted self interviews on reporting of sexual HIV risk behaviours in a general population sample: a methodological experiment. Aids 2001; 15(1):111-115.

(21) Tideman RL, Pitts MK, Fairley CK. Client acceptability of the use of computers in a sexual health clinic. International Journal of Std \& Aids 2006; 17(2):121-123. 
(22) Mitchell E, Sullivan F. A descriptive feast but an evaluative famine: systematic review of published articles on primary care computing during 1980-97. British Medical Journal 2001; 322(7281):279-282E.

(23) Frankel R, Altschuler A, George S, Kinsman J, Jimison H, Robertson NR et al. Effects of exam-room computing on clinician-patient communication. Journal of General Internal Medicine 2005; 20(8):677-682. 


\section{Licence statement}

"The Corresponding Author has the right to grant on behalf of all authors and does grant on behalf of all authors, an exclusive licence (or non exclusive for government employees) on a worldwide basis to the BMJ Publishing Group Ltd to permit this article (if accepted) to be published in STI and any other BMJPGL products and exploit all subsidiary rights, as set out in our licence http://group.bmj.com/products/journals/instructions-for-authors/licence-forms." 